\title{
Extra-Adrenal Sympathetic Paraganglioma
}

National Cancer Institute

\section{Source}

National Cancer Institute. Extra-Adrenal Sympathetic Paraganglioma. NCI Thesaurus.

Code C48576.

A benign or malignant sympathetic parag ang lioma arising from paragang lia outside the adrenal gland. Clinical symptoms are related to secretion of catecholamines.

Representative examples include the superior and inferior paraaortic and bladder paragangliomas. 